\title{
Intercultural Development: Topics and Sequences
}

\author{
Victor S a vicki \\ Western Oregon University
}

Ingrid Adams

Western Oregon University

April Wilde

Western Oregon University

Frauke Binder

AHA-International Vienna

When people travel from their own home culture to a different culture, they experience variations not only in terms of scenery and societal arrangements, but also in terms of daily routines, interpersonal interactions, and expectations. Many differences are based on the divergence in underlying values and concerns of the home versus the host culture. On a day-to-day basis, events that reveal such differences may pose threats and lead to anxiety, confusion, anger, and depression. Conversely, they may pose challenges whose resolution can lead to feelings of mastery, excitement, appreciation for aspects of the host culture, and a clearer understanding of one's home culture. The exposure and reactions to such events form the foundation of intercultural development. But what types of events are important to such development, and how do sojourners change their perspective about those events as they continue through the adjustment process? This article tracks reports of cultural events and topics deemed salient by university student sojourners over their semester of study abroad in an attempt to discover not only which topics were identified, but also the sequence in which the sojourners found those topics salient. Evidence for sequences of topic salience has implications for the education and support of sojourners both prior to departure, and during exposure to a new culture. The successful negotiation of the developmental processes in the study abroad experience can have long lasting effects for students. It is hoped that this research will increase the understanding of how to facilitate such positive development. Before reporting results of the current study, a brief review of relevant issues follows. 


\section{Intercultural Adjustment}

Adjustment to a different culture occurs on several different levels at the same time. Ward (2001) uses the ABC model to focus on the affective, behavioral, and cognitive aspects of acculturation. Affective aspects of intercultural development have been explained using features of the stress and coping literature (Lazarus, 1999). Behavioral aspects have been described using a socio-cultural learning approach based on social skills learning (Argyle, 1969, 1982). Cognitive aspects have been discussed using social identification theories (Phinney, 1990). Although it is difficult to tease these reactions apart as they are happening, the focus of the current study is on socio-cultural aspects which Ward and Kennedy (1999) defined as "The ability to 'fit in,' to acquire culturally appropriate skills and to negotiate interactive aspects of the host environment" (p. 660).

\section{Socio-Cultural Adjustment}

In order to "fit in" and acquire culturally appropriate skills, sojourners must first recognize that much of their existing knowledge and abilities, based on learning in their home culture, will not completely suffice. These skill deficits are brought to light through encounters with the host culture. Some of the required changes are overt (e.g. driving on the "wrong" side of the road), and some are "'hidden' in the sense that the participants are not fully aware of their presence until something goes wrong" (Ward, Bochner \& Furnham, 2001, p. 51). It is the quality of the encounter that demonstrates the salience of underlying cultural assumptions.

What type of encounters are likely to reveal cultural assumptions? Most simply, any encounter may serve as a vehicle for such revelation (e.g. purchasing an item in the store, waiting in line, riding public transportation). However, the number and intensity of such encounters may depend on factors such as the cultural distance between the home and host cultures. If home and host cultures are similar, the differences will be less frequent and less intense than those in very dissimilar cultures. Nevertheless, cross-cultural contact can be seen as a major stressful life event, and the buzzing confusion of shock upon entering a different culture is a predictable result (Ward, Bochner \& Furnham, 2001).

Ward and Kennedy (1999), building on the work of others (Furnham \& Bochner, 1982; Trower, Bryant \& Argyle, 1978), have identified a list of encounters and issues that may be relevant to socio-cultural adjustment. A brief sample of their 29 item scale includes "making friends," "using the 
transport system," "going shopping," "dealing with unsatisfactory service," "getting used to the local food/finding food you enjoy," "dealing with people in authority," and "understanding the locals' world view" (Ward \& Kennedy, 1999 p. 663). Longitudinally, socio-cultural adjustment is most difficult in the earliest stages of transition, but within 4 to 6 months it reaches a plateau. Thus it seems to follow a reasonably predictable learning curve (Ward, 2001, Ward, Bochner \& Furnham, 2001).

In the interests of developing a measurement instrument, Ward and Kennedy (1999) used the sum of responses to their list of topics relevant to intercultural adjustment rather than describing responses to individual topics. This method has merit, but it may conceal the possibility that different topics may gain salience at different points in the intercultural adjustment process. Reports of overall socio-cultural adjustment may obscure differences in underlying developmental processes. In addition, asking sojourners to react to a predetermined list of topics may limit the range of issues identified. Thus, Ward, Bochner, and Furnham (2001) comment, in relation to such a methodology in a similar study (Opper, Teichler \& Carlson, 1990), "we have no way of knowing if the same types of problems would have been spontaneously generated" (Ward, Bochner, \& Furnham, 2001 p. 155). The current study attempts to rectify both the averaging and topic-limiting methodological concerns.

\section{Intercultural Adjustment Development Theories}

One hypothesis concerning the development of intercultural adjustment is that adjustment proceeds via the challenges and resolutions of specific between-culture encounters, and that those encounters vary randomly based on the chance contacts that sojourners experience within a specific host culture. In this case, there would be no predictable sequence of topics since the randomness of encounters would, over time, equalize specific adjustment topics. Given previous measures of topic salience, there is no way to disprove this particular hypothesis.

An alternative hypothesis is that the salience of intercultural adjustment topics may vary depending on the stage of adjustment that the sojourner is experiencing. That is, the perception of salience of topics may be related to a predictable process of adjustment, in that "readiness" to identify and label an event as a difficulty may be connected to the particular phase of development of the individual sojourner. It is this hypothesis to which the current study subscribes. Prior to hypothesis testing, however, we will examine three theories of intercultural adjustment that may be informative. 
Several theories of intercultural adjustment have been proposed. For the purposes of the current research, we will discuss briefly the classic culture shock theory (Oberg, 1960), the Anxiety/Uncertainty Management theory (Gudykunst, 1995), and the culture learning approach (Ward, 2001).

\section{Culture Shock}

The classic description of culture shock follows three phases (Oberg, 1960). In the first phase, sojourners experience "entry euphoria" during which their enthusiasm and fascination with the host culture overshadow the day-to-day difficulties they encounter. In the course of the second "crisis" phase, encounters that reveal clashing values between home and host cultures lead sojourners to experience feelings such as inadequacy, anxiety, frustration, and anger. This is when the "shock" in culture shock becomes predominant. In the third phase, "recovery," sojourners begin to resolve some of the cultural clashes and to learn skills and knowledge to help them navigate successfully in the host culture. Given the spike in the level of discomfort and distress during the second phase, it is likely that sojourners would report more troubling encounters during the second phase than during the first and third phases. During both the "entry euphoria" and the "recovery" stages various culture clashes would be less salient, since in the first phase the sojourner would ignore or shrug off the conflicts, and in the last phase they would find such conflicts less arousing. The question remains, which topics would sojourners perceive as following the inverted "U" form of the culture shock development sequence?

\section{Anxiety/Uncertainty Management}

The personal adjustment version of the anxiety/uncertainty management developmental theory focuses on the reactions of sojourners entering new cultures and interacting with host nationals (Gudykunst, 2002). In the initial stages of cross-cultural contact, sojourners are uncertain about host nationals' feelings, attitudes, and behaviors, thus attempts to predict how best to react are fraught with anxiety. If this anxiety does not diminish, sojourners are unable to communicate effectively, and are more likely to process information in simplistic, ethnocentric ways, thus perpetuating the anxiety. Alternatively, if sojourners can be open to new information and creatively develop new ways of thinking that take into account the perspectives of host nationals, the probability of successful communication increases and anxiety is reduced. Over repeated, successful encounters, sojourners continue to reduce their anxiety. Thus the salience of cultural clashes is driven by the level of uncertainty. More 
clashes would be reported early when uncertainty is high, and fewer clashes would be reported later when uncertainty is lower. The question remains, which topics create the most uncertainty in sojourners, and which topics are likely to decrease in intensity of anxiety as experience with the host culture continues over time?

\section{Cultural Learning}

The basic change dimension of the cultural learning developmental approach is the learning curve. Based on social and experimental psychology, the assumption is that sojourners have difficulties in intercultural adjustment because they lack "culture-specific skills that are required to negotiate the new cultural milieu" (Ward, 2001 p. 413). Early in their exposure, sojourners are likely to display skill deficits related to the host culture, and to respond to discriminative stimuli in the host culture by over-generalizing responses that would be appropriate in their culture of origin. As learning proceeds through exposure to the host culture, skills increase and competence in the culture grows. From this developmental point of view, salience of topics would increase over time as sojourners developed the knowledge and skills to notice and respond to cultural clashes. As their repertoire of skills and knowledge increases, so would the number of new situations into which they would place themselves. The question remains, which topics would sojourners identify as increasing over time as their skill repertoire expands?

A comparison of the three developmental theories of intercultural adjustment suggests that if topic salience does follow a sequence, the three theories predict different patterns. The culture shock pattern would show a peak of salience of topics during the middle of a sojourn both preceded and followed by lower salience. The anxiety/uncertainty management theory would predict a pattern of high initial salience of topics followed by steady decrease as anxiety is resolved. The cultural learning approach would predict a pattern of low initial salience based on lack of culture specific skills, followed by a steady increase in salience as skills lead to greater exposure to various aspects of the culture. The mechanisms by which an event would become salient are different in the three theories. The literature does not indicate the dominance of one pattern over another. Our hypothesis remains that there will be a sequence of topic salience over the sojourn in the host culture. 


\section{Me t hods \\ Participants}

Participants were 72 U.S. university study abroad students staying for three months to study in a major European city. They were traditional student ages between 19 and 25. Men comprised $53 \%$ of the sample and women $47 \%$ . The students came primarily from the U.S. Midwest and Pacific Northwest. Most $(60 \%)$ did not speak the language of the host culture upon first arriving. A class in the language of the host culture was required for all students appropriate to their level of language proficiency. All classes in which they enrolled were taught in English with only fellow U.S. students. Students lived with host culture nationals in a typical home stay arrangement. The sample included students from four different semesters spanning a two-year period.

\section{Materials}

Students in a required intercultural communication class were assigned to write a report on a salient cultural issue nine or ten different times during their three month sojourn. The identification of such issues was entirely chosen by the student; no lists or categories of issues were proposed to choose from. The reports were to be spontaneous and contemporaneous rather than retrospective. The issues gained salience to the students only with regard to their own experiences and perceptions; thus they conformed to the definition of "critical incident" as "an event that matters" (Ward, Bochner \& Furnham, 2001, p. 5). Students were to write about this issue following the Description, Interpretation, Evaluation (DIE) format in which their report first indicated the Description of the event in objective terms; then an Interpretation of the event which focused on identifying underlying aspects or values of the host culture that could be at play in causing the specific event; and finally an Evaluation including why they thought the event occurred from their own viewpoint and how they felt about it (Landis, Bennett, \& Bennett, 2004). In all, over the four different semesters, 491 DIE reports were submitted. Subsequent analyses were conducted using the DIEs as the source of information.

\section{Procedures}

The construction of the topic coding system and subsequent coding of DIEs was a multi-step process following principles of qualitative research (Liamputtong \& Ezzy, 2005). First, an initial team of researchers read the DIEs for significant statements (Moustakas, 1994) that identified salient cultural issues. A total of 165 relevant meanings were identified. Second, these meanings were 
clustered into 23 different nominal categories on the basis of the nature and focus of the students' experience (Moustakas, 1994). These categories were designed to be comprehensive and mutually exclusive based on overlap of topic themes, discrimination between themes, and similarity of themes to those previously found in the literature (Creswell, 1998). Third, a three-person panel of judges then classified each DIE report into one of the 23 nominal categories. Inter-rater agreement for classification was $75 \%$. Disagreements in coding were resolved through discussion. The categories identified are listed below.

1. Assertion: The ability and ease with which participants were able to make their needs and desires known to people in the host culture.

2. Cross-Cultural Comparisons: A comparison of U.S. and host culture values and behaviors as compared with other European cultures that the participants encountered during their travels.

3. Cultural Bias: Bias of the host culture, usually against the U.S. culture; anti-Americanism.

4. Cultural Rule: General differences in overall values of the host culture with the home culture, especially with regard to overt public interactions with strangers.

5. Communication: Usually the lack of accurate understanding communicated between participants and members of the host culture, often based on differing communication styles.

6. Food: Differences in food preferences, presentation, and availability between the host culture and the home culture

7. General Environment: Differences with regard to environmental concerns (e.g. recycling), features of architecture, and civic actions with regard to environmental issues.

8. Home stay Environmental: Concerns about the physical environmental conditions in the home stay setting.

9. Home stay Social: Concerns about the interpersonal interaction occurring while in the home stay setting.

10. Hygiene: Differences in levels of cleanliness and concern for habits of personal hygiene.

11. Intrapersonal: Reflection on personal affective, cognitive, and existential reactions with regard to the intercultural adjustment process.

12. Transportation: Issues concerning public transportation, differing requirements for walking, and differences in expectations concerning personal travel. 
13. Language: Concerns with the use of the host culture language and feelings of inadequacy concerning use of a foreign language.

14. Public Displays of Affection: Differing expectations for romantic and sexually related behavior in public settings.

15. Privacy: Differing expectations concerning what types of behavior and events should be shared versus held private, and mechanisms by which privacy was maintained.

16. Public Interactions: Differing expectations about where specific social events were most likely to take place, and the frequency of unexpected public behaviors.

17. Public Meeting Places: Different expectations concerning the availability and use of public spaces.

18. Smoking and Drinking (Health): The prevalence of smoking and the differing expectations and laws regarding drinking of alcoholic beverages.

19. Social Contact: Contact with others from the host culture, not related to the academic or home stay environments.

20. Social Conversation Preference: Differences in the intensity of conversations concerning politics and other "sensitive" subjects.

21. Social Preferences: Differences in acceptable general behavior of daily living such as shopping, advertising, expectations concerning appropriate dress, etc.

22. Social Rules: Differences in expectations of the "rules" of social interaction (e.g. eye contact, personal space), especially differences in what was socially appropriate versus inappropriate.

23. Social Value of Time: Differences in the pace of events, and the value placed on informal, non-work related activities.

The reports were then organized by the date upon which they were submitted. For the analyses described in this study, reports were deemed as falling into three different time periods: Early (participants' first three DIEs), Middle (participants' second three DIEs), and Late (the last three or four DIEs).

\section{Results and Discussion \\ Overall distribution of intercultural adjustment categories}

When looking simply at the percentage of each intercultural adjustment category reported (figure 1), it is clear that, overall, some categories were much more salient to participants than others. For example, Social Preferences, Social Rules, and Public Interactions all were reported $8 \%$ or more times overall. 
Assertion, Food, Intrapersonal, and Public Display of Affection were all reported less than $2 \%$ of the time overall. These differences were significant (X2 (550) $=655.28, \mathrm{p}<.001)$. The most reported categories contain events that coincide quite closely with those reported by others (Spradley \& Phillips, 1972; Ward \& Kennedy, 1999). Sojourner attention to various categories related to intercultural adjustment was not randomly distributed. There were no significant differences in percentages of category reports between men and women.

Figure 1. Percentage of reports of intercultural adjustment categories

\section{Distribution of intercultural adjustment categories over time}

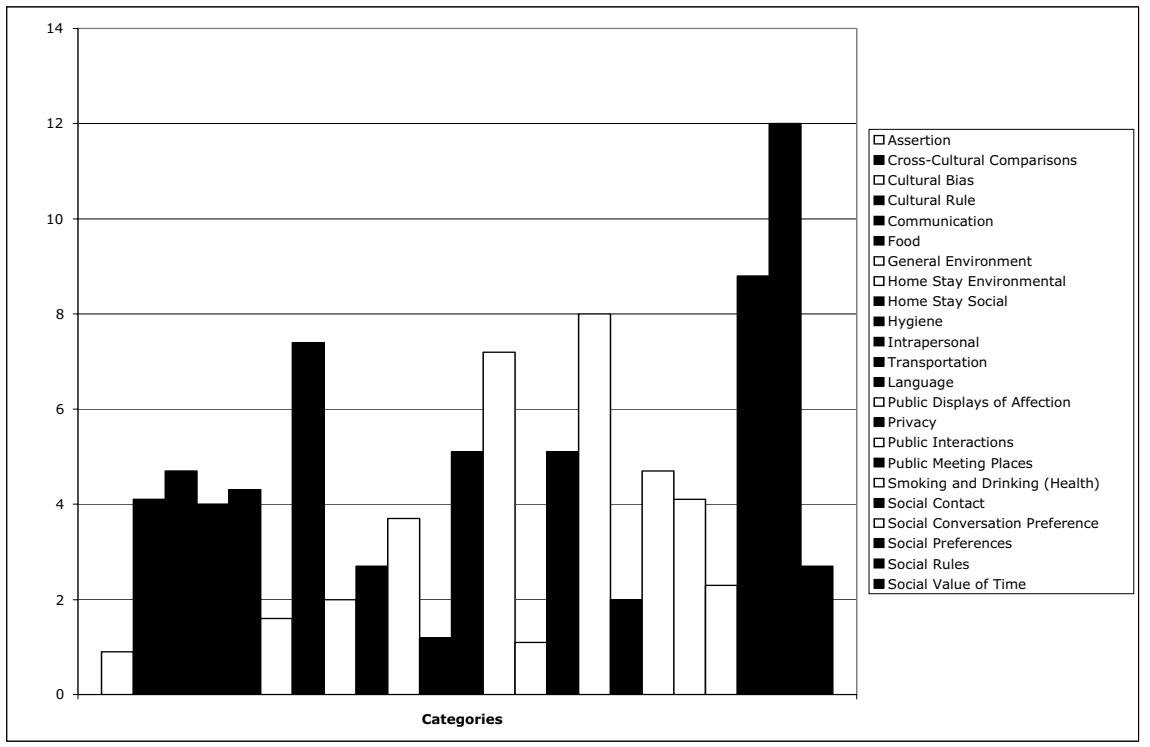

In order to simplify discussion of the changes in intercultural adjustment categories over time, three different analyses will be presented depending on the manner in which the changes occurred. In each analysis the three-month sojourn was broken into three time periods: Early, Middle, and Late. Discussion will be limited to those categories which showed substantial salience to the study abroad students (i.e. the number of reports equaled or exceeded. 6\% for at least one time period).

\section{Categories that decreased over time.}

Figure 2 indicates those categories in which there was a decrease of reports from Early to Late in the sojourn. For Communication $\left(X^{2}(2)=15.93, p<.001\right)$ and Social Contact $\left(X^{2}(2)=12.74, p<.01\right)$ the differences over the three time 
periods reached statistical significance, but not for Public Interactions. The trend with these categories was for the salience to be much higher early in the sojourn and lower late. For Communication much of the early experience of students focused on understanding others in the host culture and making themselves understood. Independent of specifically mentioned language issues, the concern about communication and miscommunication focused both on interpersonal communication patterns and on expectations about how communication was to occur.

Figure 2. Percentage of reports of intercultural adjustment categories that decreased over three time periods

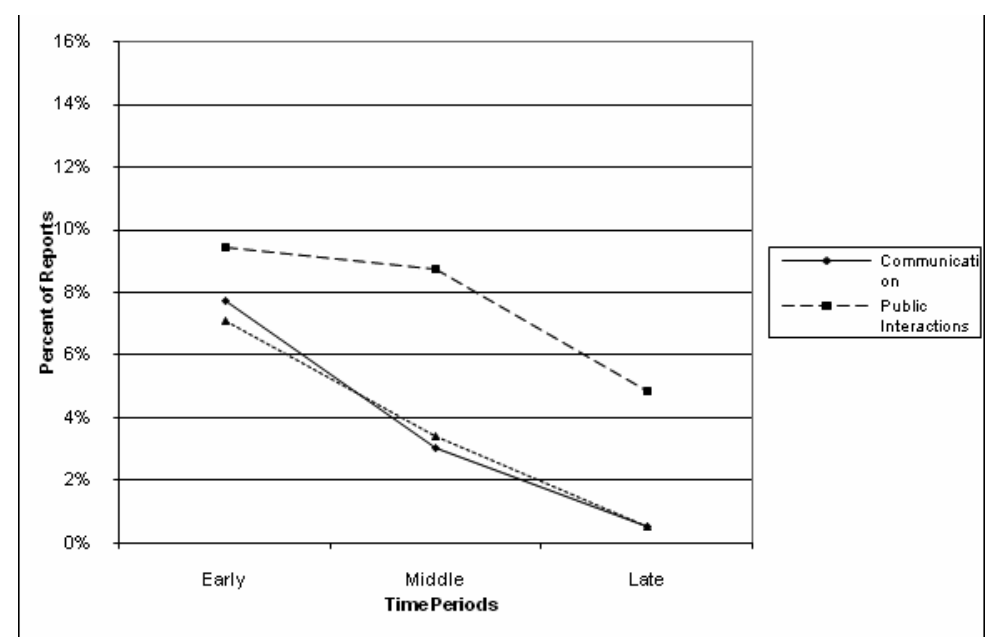

Throughout their stay, the students continued to learn these patterns and expectations, so that by the end, they were communicating better, and misunderstandings were not as mysterious and shocking. For Social Contact the decrease from early to late probably reflects the newness and difference of the host culture at the beginning of the sojourn and the familiarity at the end. As cultural differences became more recognizable and as students developed an understanding of how to react, incidents of shocking contact with people in the culture most likely faded into the background. For Public Interactions a similar familiarity most likely accounted for the drop in reports from early to late. Some of the early concerns focused on urban phenomena such as dealing with panhandlers. Not only did the students become more adept at handling these incidents over time, but also their attitude and bearing probably changed enough so that they no longer stood out at foreigners and therefore they became less of a target for such interactions. These three categories that decreased over the three time periods illustrated that the relevance of intercultural adjustment issues can 
decrease over time consistent with the anxiety/uncertainly management theory of development. That is, students who initially generated quite a bit of anxiety while dealing with the different/strange aspects of the host culture, over time learned both to manage the uncertainty inherent in living in a different culture. They were able to decrease the attendant anxiety through developing routines to cope with recurring cultural issues.

\section{Categories that changed trajectory}

Figure 3 indicates those categories in which there was a change in trajectory of reports across Early to Middle to Late in the sojourn. These four categories include Language, Privacy, Health, and Social Rules. No changes in these categories reached statistical significance. First, Language showed a dip in the middle time period preceded and followed by a higher percent of reports. The most likely scenario for this pattern was that students were very concerned about their lack of fluency in the host culture language early in the sojourn, but then learned enough of the language to have satisfactory interchanges by the middle of their stay in public settings with strangers such as store clerks, bus drivers, etc.. However, later they discovered that deeper conversations with acquaintances who were not facile with English left them again feeling challenged by their lack of fluency in the host culture language.

Figure 3. Percentage of reports of intercultural adjustment categories that changed over three time periods.

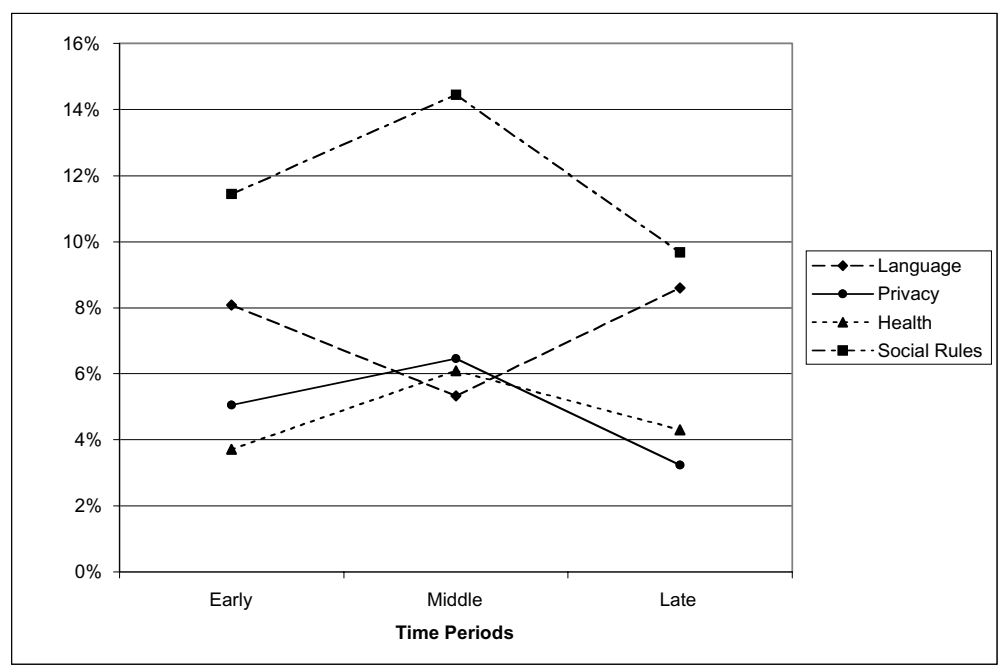


The other three categories that changed trajectory did so in a similar pattern in which lower early and late reports bracketed a higher percent of reports in the middle time period. For both Privacy and Health (Smoking and Drinking) it is likely that initially students were not as aware of the degree of difference between their home culture and the host culture on these issues because they were preoccupied by other cultural differences. When more pressing adjustment demands waned, these two concerns became more relevant. Then by the end of the sojourn students had adapted to these cultural issues as well; therefore, the percentage of reports fell.

The Social Rules category was the most salient of all 23 categories during the first two time periods. Early in their sojourn students noticed social faux pas and were troubled by them. However, as they adjusted to other aspects of the host culture, they began to put themselves into more new and different situations for which they had not learned the rules of behavior for the host culture. This increase in reports in the middle time period probably represented the level of struggle that they had concerning cultural differences surrounding simple, everyday interchanges that were habitual in their home culture but required focus and heightened awareness in the host culture. The drop in percentage of reports in the late time period probably indicates some success at mastering the host culture rules of behavior, though the number of reports remained high in comparison to all other categories. With the exception of the Language category, the other categories that changed trajectory over the three time periods showed a pattern consistent with the developmental theory of culture shock. In this theory, as in the anxiety/uncertainty management theory, the driving force for salience is emotional arousal. Early enthusiasm and naiveté were followed by some anxiety, irritation, and bewilderment at cultural differences, to be then followed by the resolution of many of those reactions as the cultural patterns became more familiar and understandable.

\section{Categories that increased over time.}

Figure 4 indicates those categories in which there was an increase in percentage of reports from Early to Late in the sojourn. For Cross-cultural comparisons $\left(X^{2}(2)=15.18, p<.001\right)$ and General Environment $\left(X^{2}(2)=\right.$ $18.67, p<.001)$ the differences over the three time periods reached statistical significance, but not for Social Preferences. The general trend with these categories was for the salience for participants to be much higher later in their sojourn and lower early. For Cross-cultural comparisons, this difference probably stemmed from the individual travel activities of the students. Early in the 
Figure 4. Percentage of reports of intercultural adjustment categories that increased over three time periods

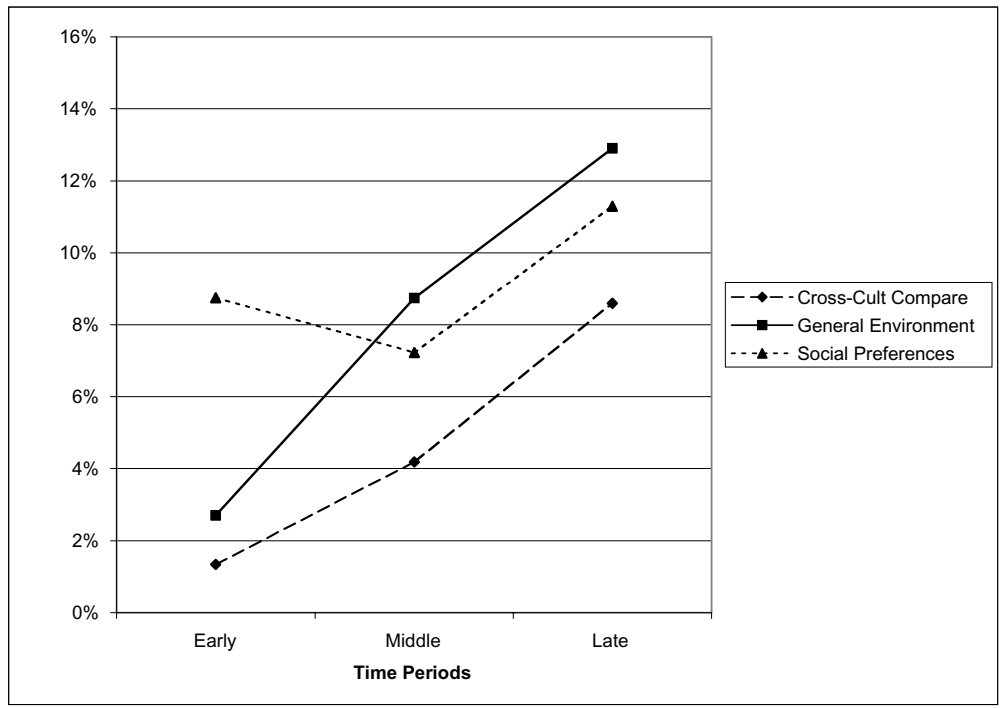

semester they remained close to their host city, but later they traveled to other European countries so that they were faced with comparisons between their home culture, their main host culture, and the cultures of the other countries to which they were exposed on their travels. Differences in General Environment may have become more salient as the students became more aware of features of their host culture that dealt with conservation and other environmental concerns. These may have become relevant only after some adjustment to the host culture had taken place. Social Preferences probably increased over time as students immersed themselves in the routines of daily living and exposed themselves to a broader range of situations and activities in which such preferences could be discovered. Once having mastered some of the simple patterns of behavior, they could delve more deeply into those about which they were initially unaware. These three categories that increased over the three time periods illustrated that the relevance of intercultural adjustment issues can increase over time consistent with the culture learning theory of adjustment. That is, students continued to learn about various aspects of their host culture, and some of that learning was related to opportunities that unfolded during the sojourn. Topics that were not particularly salient at the beginning gained relevance as the students passed through stages of immersion into the host culture, and were exposed to a wider range of issues. 


\section{Conclusions}

In summary, the relevance of specific categories of intercultural adjustment issues was not randomly distributed, nor did the categories occur with equal frequency over the length of the sojourn. The patterns of change in reports of categories over time suggests that participants found some categories more relevant at different times. In addition, the fact that three different patterns of change appeared seems to indicate that several different phenomena might have caused the patterns.

One likely candidate as a causal factor underlying differing patterns of reports is the developmental stage or process involved in participants adjusting to a foreign culture. Results of the current study seem to support the notion that more than one theory of development may be operating at the same time. Three different theories might predict three different patterns of change in the relevance of topics. One possibility is that the theories of intercultural adjustment are not mutually exclusive; rather, different categories of issues are more explainable using one theory versus another.

For example, with regard to Social Rules, the culture shock hypothesis might have more influence since early ignorance of issues was followed by heightened concern over those issues followed by mastery and decrease in relevance. On the other hand, attention to issues in the General Environment might be more amenable to the social learning theory in which people undergoing intercultural adjustment might become more attentive over time to specific issues as they develop skills and knowledge that make them more competent to navigate the host culture. What is hidden or difficult to understand in the beginning becomes more understandable and central to comprehending the host culture as time goes by. Finally, concerns about Communication might fit better with the Anxiety/ Uncertainty Management theory in which the relevance of this issue decreased steadily over time as the difficulties were understood and mastered. Rather than postulate that one theory fits all intercultural adjustment issues, it might be more accurate to assign specific issues to specific theories of development. It may also be more useful to begin to hone in on the possible relationships between types of concerns and types of developmental processes.

When averaging the three different patterns (increasing, decreasing, and inverted U shaped) the results are consistent with Ward and Kennedy's (1999) findings that early phases of exposure to a different culture places intense demands on sojourners, who begin to adjust so that later the level of stress diminishes. High early and middle sojourn demands are followed by late-inthe-sojourn expanded exploration and appreciation of the host culture. To be 
sure, sojourners continue to encounter culture clashes as they expose themselves with ever-increasing intensity to the host culture. However, after the initial adjustment process, such misunderstandings might not be as shocking and mysterious, and therefore are perceived with less anxiety. Breaking apart the average response revealed the multiple patterns that had been masked by averaging. An area for further empirical study is the notion that successful reduction of stressors in the early stages sets the stage for later freedom and motivation to explore the host culture in more depth.

Implications for student advisors, study abroad educators, and personnel in study abroad locations have several emphases. First, pre-departure and early on-site orientations might emphasize some topics and touch lightly on others. For example, rules of social interaction and communication outweigh food preferences and discussions of perceptions of time as areas of students concerns. There is some predictability about when and how intensely various topics will arise. Given that such orientation activities are likely to suffer time constraints, some guidance concerning prioritizing topics may be useful. Second, just the notion that change in perception and level of arousal will occur in an approximate developmental sequence may be informative. Students who can anticipate such changes may be able to tolerate the negative emotions that may accompany early stages with the realization that they will move beyond such responses. Likewise, study abroad educators and coaches may be able to sequence their courses and assistance to anticipate the emergence of topics. Finally, all developmental theories of intercultural adjustment agree that early successes in adjustment are necessary to move students toward later, overall success of study abroad placement. Anticipating when and where to intervene with individual students may increase the probability not only that early developmental movement occurs, but also that later delays or plateaus can be addressed.

Although the current study addresses some of the methodological concerns raised in previous considerations of topics of intercultural adjustment for sojourners, these findings need replication. Clearly, the categories used in this research were culture specific, and linked to the stressors generated by academic demands and the structure of living arrangements. Different arrangements may yield a different set of categories. Yet, the finding that sojourners evaluated the salience of topics differently across time suggests that pre-departure training, and during-sojourn coaching and support can be more precisely focused to address concerns as they evolve, thus leading to a more efficient and effective transition of sojourners into their host culture. 


\section{References}

Argyle, M. (1969). Social Interaction. London: Methuen.

Argyle, M. (1982). Intercultural communication. In S. Bochner (Ed.) Cultures in Contact" Studies in cross-cultural interaction (pp. 61-80). Oxford: Pergamon.

Creswell, J. W. (1998). Qualitative Inquiry and Research Design. Thousand Oaks, CA: Sage.

Furnham, A. \& Bochner, S. (1982). Social difficulty in a foreign culture: An empirical analysis of cultural shock. In S. Bocher (Ed.) Cultures in contact: Studies in cross-cultural interaction (pp. 161-198). Oxford: Pergamon Press.

Gudykunst, W. B. (1995). Anxiety/uncertainty management (AUM) theory. In R. L. Wiseman (Ed.), Intercultural communication theory (pp. 8-58). Thousand Oaks CA: Sage.

Gudykunst, W. B. (2002). Intercultural communication theories. In W. B.

Gudykunst \& B. Mody, Handbook of international and intercultural communication 2nd Ed. (pp. 183-205). Thousand Oaks, CA: Sage.

Liamputtong, P. \& Ezzy, D. (2005). Qualitative Research Methods (2nd ed.). London: Oxford University Press

Landis, D., Bennett, J. M., \& Bennett, M. J. (Eds.) (2004). Handbook of intercultural training 3rd Ed. Thousand Oaks, CA : Sage Publications.

Lazarus, R. S. (1999). Stress and Emotion. New York: Springer Publishing.

Moustakas, C. (1994). Phenomenological Research Methods. Thousand Oaks, CA: Sage.

Oberg, K. (1960). Cultural shock: Adjustment to new cultural environments. Practical Antbropology, 7, 177-182.

Opper, S., Teichler, U. \& Carlson, J. (1990). Impacts of study abroad programmes on students and graduates. London: Jessica Kingsley Publishers.

Phinney, J. S. (1990). Ethnic identity in adolescents and adults: Review of research. Psychological Bulletin, 108. 499-514.

Spradley, J. P. \& Phillips, M. (1972). Culture and stress: A quantitative analysis. American Anthropologist, 74, 518-529.

Trower, P., Bryant, B., \& Argyle, M. (1978). Social skills and mental health. London: Methuen.

Ward, C. (2001). The A, B, Cs of acculturation. In D. Matsumoto, The Handbook of Culture and Psychology. (pp. 411-445), Oxford: Oxford University Press.

Ward, C., Bochner, S., \& Furnham, A. (2001). The Psychology of Culture Shock 2nd Ed. London: Routledge.

Ward, C. \& Kennedy, A. (1999). The measurement of sociocultural adaptation. International Journal of Intercultural Relations, 23. 659-677. 